\title{
DE LORD BYRON A JOSÉ DE ESPRONCEDA: IMAGEN Y ESPÍRITU ROMÁNTICO EN LA FIGURA DEL PIRATA
}

\author{
FROM LORD BYRON TO JOSÉ DE ESPRONCEDA: \\ IMAGE AND ROMANTIC SPIRIT \\ OF THE FIGURE OF THE PIRATE
}

\author{
Sergio ARLANDIS \\ Universitat de València \\ sergio.arlandis@uv.es

\section{Agustín REYES TORRES} \\ Universitat de València \\ agustin.reyes@uv.es
}

\begin{abstract}
Resumen: Muchos son los estudios que se han ocupado de la poesía de José de Espronceda en comparación con la de Lord Byron, como si la necesidad de establecer una conexión con el romanticismo europeo fuera necesaria para legitimar su originalidad. En el presente trabajo no solo llevamos a cabo un recuento de posibles fuentes bibliográficas de la figura del pirata en el poema "Canción del pirata", sino que realizamos una profunda comparativa de sus respectivas figuras poéticas, partiendo de otros textos coetáneos, como el de Lasso de la Vega, por ejemplo. Se trata, en definitiva, de un debate aún no cerrado del todo.
\end{abstract}


Palabras clave: Romanticismo. Símbolos. Arquetipo, Malditismo. Lord Byron. Espronceda.

\begin{abstract}
There are many studies that have dealt with the poetry of Jose de Espronceda in comparison with that of Lord Byron, as if the need to establish a connection with European Romanticism was necessary to reward its originality. In the present work we not only carried out a count of possible bibliographical sources of the figure of the pirate in the poem "Canción del pirata", but we realized a deep comparative of its respective poetic figures, starting from other contemporary texts, like the one of Lasso de la Vega, for example. It is, in short, a controversy still not closed at all.
\end{abstract}

Key Words: Romanticism. Symbols. Archetype, Malditism. Lord Byron. Espronceda.

\title{
1. UN DEBATE INICIAL: EL SUSTRATO BYRONIANO EN ESPRONCEDA
}

Muchos son ya los calificativos que el poeta extremeño — de origen familiar andaluz - José de Espronceda, ha recibido a lo largo de los años, y estos ciertamente no siempre se le han atribuido desde la admiración que su figura y su obra debieran suscitarnos: a veces su nombre ha sido reconstruido bajo la confusa máscara de lo arquetípico, con esa imagen preñada de etiquetas, tan estereotipadas como insuficientes según va creciendo el conocimiento del lector sobre lo analizado. Otras veces, en cambio, mediante juicios injustos en las valoraciones finales sobre su obra, sobre su originalidad e incluso sobre su actitud política y social, acomodada a pesar de todo ${ }^{1}$. Desiguales opiniones que abren posibilidades argumentativas cada vez que el crítico se acerca con avidez a textos poéticos, novelísticos y teatrales de José de Espronceda. Aunque dichas valoraciones siempre pueden ser utilizadas como fuentes que faciliten la prudente tarea de rastrear las influencias del autor y de sus libros. Con

1. Un debate que ya planteó Domingo Ynduráin (1971) frente a estudios como el de Ricardo López Landeira (1975 y 1985), Diego Martínez Torrón (1999), Luis Caparrós Esperante (1989) o Robert Marrast (1989) entre otros. Un estado de la cuestión que el estudio heterogéneo, coordinado por José Luis Bernal Salgado y Miguel Ángel Lama (2010), ha vuelto a poner de actualidad. 
todo, el conflicto real estribaría en tratar de cuestionarse si esta dicotomía entre un Espronceda renovador y otro epigonal no es solo producto de un erróneo planteamiento de base.

Recientemente Diego Martínez Torrón, en la edición de las Obras Completas $^{2}$ de Espronceda, realizaba una interesante revisión del romanticismo español, rompiendo quizá con los moldes de lo estipulado hasta la fecha: hartos de leer que el Romanticismo en España fue escaso y tardío por norma, Martínez Torrón señalaba que "hay que mantener que España no llegó tarde y mal a la modernidad y que nuestro Romanticismo fue coetáneo del inglés, francés o alemán, que son los más tempranos. Lo que ocurre es que el Romanticismo es diferente en cada país, por el nacionalismo específico a él asociado" (Martínez Torrón, 2006: 15). No obstante (y para no radicalizar erróneamente sus palabras), también entiende que las dificultades políticas del país durante estos años de convulsión social cortaron de raíz una línea evolutiva que - bajo la propia consideración de Martínez Torrón- nunca hubiera ido a la cola de Europa, como finalmente ocurrió, sino por una senda diferente e, incluso, disidente. Y este debate, tan sumido en la valoración de lo que se entiende por romanticismo español y por la naturaleza bifacial de su desarrollo en las letras españolas, afectó de lleno a uno de los máximos representantes de dicho período, pues si el romanticismo español vino a considerarse pasivo recipiente del espíritu romántico europeo, de estirpe más pura y revolucionaria (por convicción y no por moda), la obra de Espronceda quedó en un segundo plano, por su novedad contextual y por su trascendencia literaria. Por tanto, uno de los autores más célebres, celebrados, imitados y leídos de la literatura española no dejaría de ser cenáculo de voces ajenas cuyo eco se dejaría entrever en su más estimable superficie expresiva, lo que, en cierto modo, justificaría afirmacionestan desafortunadas, a nuestro parecer, a pesar del ingenio que muestrancomo la que ha realizado recientemente Tamara R. Williams: "El que Espronceda sea el escogido para resaltar este tema no sorprende ya que se sabe que su 'Canción de los piratas' [sic.] además de ser canción de piratas es canción pirateada, es decir, expone varias semejanzas con dos obras anteriores: The Corsair de Lord Byron y L'Ami de la tempete, imitation

2. Las citas del poema "Canción del Pirata" han sido extraídas de esta misma edición: como no existe variación alguna en el texto con el resto de ediciones del poema, no creemos necesario indicar bibliográficamente su número de página. 
de Lord Byron" (Williams, 2004: 479). Esta valoración que, en cierto modo, vendría a sumarse a una larga lista de apuntes críticos de igual o equivalente apreciación sería contrarrestada por aquellos que sí vieron en Espronceda un estilete estético, abriendo nuevos caminos para la literatura española por encima de deudas, préstamos, influencias o demás ajustes de una evolución interior, lógica y obligada en cualquier escritor, sea cual sea su cometido, su época o su formación.

Seguramente, uno de los ejemplos más claros de este debate lo encontramos en la siempre controvertida discusión en torno al byronismo de Espronceda. Una cuestión que ya cuenta con una amplia nómina de detractores y seguidores casi, incluso, coetáneos a los dos poetas. Por ejemplo, el crítico (y poeta) Marcos Arróniz escribía en 1851 un artículo titulado "Espronceda", en el que afirmaba que el poeta pacense carecía de rival poético en territorio español y que solo Byron, en Europa, estaba a su altura literaria:

Puede decirse con justicia que Espronceda es el Byron de España: ved, la misma belleza física, el mismo preclaro talento, la misma sensibilidad ardiente, la misma audacia y energía, igual vida desenfrenada e idéntico entusiasmo por lo grande, que a uno lo impele a combatir por Grecia y al otro a ofrecer su brazo en defensa de la oprimida Polonia (Apud. Campos, 2007: 40) .

Semejante fascinación había expresado José Zorrilla, quien lo definió, según recogió más tarde Joaquín Casalduero (1983: 33), como "la personificación del clasicismo apóstata del Olimpo, y lanzado, Luzbelpoeta, en el infierno insondable y nuevamente abierto del Romanticismo..." cuya imagen no dejaba de asociarse — aunque implícitamente- a la del Byron más audaz, irreverente y romántico. En fechas coincidentes a las de Arróniz, Ramón de Mesonero Romanos, en su Escenas matritenses, hacía un rápido recorrido por la biografía de Espronceda, donde, nuevamente, acabaría vinculándose a Byron y, sobre todo, abonando su imagen estereotipada:

3. Para una mejor lectura de los textos decimonónicos y de principios de siglo XX (o más actualizada en todo caso), hemos adaptado ortográficamente las citas extraídas, conocedores de que tal licencia solo puede justificarse por hacer más fluida la posible lectura del presente trabajo. 
De Lisboa, huyendo de la persecución del gobierno español, pasó a Londres donde estudió a Shakespeare, Milton y Byron, aficionándose particularmente a este último con cuyo genio simpatizaba mas el de nuestro poeta [sic.], hasta el punto de recordar a Byron muchas de sus producciones. Fijó después su residencia en París, y entusiasta por la libertad, tomó parte en las jornadas de julio de 1830, hallándose en las barricadas del Puente de las Artes (Mesonero Romanos, 1851: III-IV).

Cabe, pues, tener presente el hecho de que comparar no implica subordinarse a una idea, a una estética o a un autor y quizá, esta conclusión fuera el principal fundamento de un enojado Juan Valera, quien veía desventajosa la comparación entre los dos poetas:

Dicen los envidiosos que Espronceda no hace sino imitar a Byron. Yo confieso que le imita en algunas digresiones del Diablo Mundo, en el Canto del Pirata, y en la carta de doña Julia. Pero estos envidiosos no comprenden o no quieren comprender que don Félix de Montemar no está tomado de Byron y vale tanto o más que los héroes de Byron (Valera, 1854: 622).

De igual forma, Esteban Pujals, en su estudio comparado de 1951, titulado Espronceda y Lord Byron, observaba que la resonancia de la obra de Byron fue tan grande en el mundo romántico "que no es extraño que, a más de un siglo de distancia, sus ecos se confundan todavía con la fama de uno de nuestros más altos valores literarios del siglo XIX" (Pujals, 1951: 205). Pujals ofrecía un detallado repaso de cómo surgió y se desarrolló la leyenda del byronismo de Espronceda para concluir que la confusión entre ambos autores no era más que eso: una leyenda procedente de un error inicial por parte de nuestros antepasados románticos y de una insuficiente o desencaminada observación (Pujals, 1951: 212). En este sentido, no cabe duda de que parte del debate estribaba en la consideración de Espronceda como alter ego byroniano a la española por la identificación de dos autores cuya voz, semblanza, trayectoria vital y hechos, los asociaban - y acaso los emparentaba - con esa propensión romántica de generar personalidades 
fuertes, individualistas y significativamente reconocibles. De esta manera, pasaríamos de un parentesco a una coincidencia o simultaneidad de caracteres, por encima de curiosas similitudes. Y a tal equivalencia nos conducen, por ejemplo, las palabras de Pedro Antonio de Alarcón en su breve relato, Dos ángeles caídos: "Mil hombres dolorosos, mil corazones heridos, mil víctimas de sus sentimientos, me dijeron 'Desconfía' y desconfié. Me nutrí de la hiel de Byron, del desdén de Espronceda, del frenesí de Jacobo Ortiz" (2017: 12).

Afirma Martínez Torrón que el estudio de José Cascales $(1914,1932)$ sobre el poeta español "falsea" buena parte de su imagen como creador de clara estirpe romántica, aunque sí coincide con el mismo cuando "minimiza la influencia de Byron sobre el poeta español" (2006: 32), pues como añadirá más adelante:

Es cierto que la crítica positivista [a la que se asocia el propio Cascales], con Bréreton a la cabeza, también Churchman antes, ha rebasado los límites de lo creible en la fijación de fuentes en Espronceda. De creer a estos críticos positivistas Espronceda sería un autor sin originalidad alguna, deudor de Byron — cuya sombra persigue a nuestro autor, siendo como creo su poesía bien diferente-, de Voltaire, de Tasso, de Fray Luis de León, de Garcilaso, etc. (Martínez Torrón, 2006: 37).

Si bien, el propio Cascales, más que negar dicha influencia, la calificó de "inútil", aunque sin dejar muy claro si dicha inutilidad vino dada por una infructuosa imitación de $s u$ admirado Byron (Cascales, 1932: 6) o si esto era debido a que los resultados no eran satisfactorios, básicamente porque más adelante él mismo afirmó que Espronceda debía considerarse "tan grande, cuando menos, como Byron, Goethe, Leopardi y los más eminentes del mundo" (1932: 10). Sin duda se trata —a nuestro parecer- más de lo primero que de lo segundo. Efectivamente, Byron es una sombra que recorre los versos de Espronceda, pero cuya lumbre no es propia de la crítica actual: ya en su tiempo fue visto de esta manera, pero toda esa corriente de opinión que ha llegado hasta nuestros días tiene claros referentes bibliográficos, como son los estudios de Philipe Churchman (1909, 1909b), el propio Esteban Pujals (1951), Barbara Dale 
(1980), Donald Shaw (1988) y M. Ridenour (1991). En su mayoría, dichos estudios se orientaron a la correspondencia (apuntada por Valera) del Félix de Montemar esproncediano con el Don Juan de Byron. Opinión a la que se fueron sumando, muy ocasionalmente, otros trabajos como los de Joaquín Casalduero (1961, 1983), quien, a pesar de negarse a establecer una comparativa entre los dos autores, se vio forzado a remarcar ciertos paralelismos inevitables entre la obra de Byron y la de Espronceda, además de reconocer que el poeta inglés se encontraba entre sus más explícitas influencias (Casalduero, 1983: 43). Igualmente, los estudios de Guillermo Carnero (1974), Romero Tobar (1994), Jenaro Talens (1975) o Richard A. Cardwell (2004), entre otros, se hacen eco de esta relación que, necesariamente, debía ser de dependencia entre el poeta español y el inglés. Incluso a la hora de valorar el impacto literario de Byron en Europa, una vez se llega a territorio español, siempre se hace en los siguientes términos: "Even such a rapid summary helps to contextualize the appearance on the literary scene of that Young poet so often designated 'the Spanish Byron', José de Espronceda" (Flitter, 2004: 138) o "it is clear that Espronceda had found in Byron a soul-mate, a voice that spoke to his own in similar terms" (Cardwell, 2004: 158); hasta el punto de afirmar que "once Espronceda passed away, Spanish byronism ceased" (Cochran, 2005: 77). Valoraciones, todas ellas, que nos deben situar ante un marco crítico tan extenso en su manifestación como reducido en sus conclusiones finales.

Fue Robert Marrast - a propósito del propio texto de El estudiante de Salamanca - quien trató de ubicar al personaje esproncediano dentro de una misma gama de personajes de estirpe romántica como el Moor de Schiller, el Robin Hood de Walter Scott, el corsario y el Lara de Byron, el don César de Bazán o el Hernani de Víctor Hugo (1970: 37). Y en este sentido el propio Marrast recalcaba que se debía superar la dicotomía entre coincidencia e imitación para una justa valoración de la obra esproncediana:

cotejar algunos aspectos literarios o estilísticos puramente formales constituye un análisis superficial, ya que se reduce a un simple mimetismo lo que en realidad responde a una visión de mundo en gran parte común a dos escritores, que si bien se expresan por medios que inevitablemente tienen entre sí algunas semejanzas, es cierto que no basta levantar 
acta de ellas para esgrimir argumentos a favor o en contra de la originalidad de Espronceda (1989b: 59).

Del mismo modo, Esteban Pujals determinaba que los dos autores adquirían su ideología romántica de las mismas fuentes y que Espronceda no derivaba de Byron, como podría suponerse:

Salta a la vista que, por encima de todas las diferencias presumibles de fondo y expresión, Byron y Espronceda pertenecen al mismo movimiento. A veinte años de distancia uno de otro, ambos aprovechan las lecciones de los enciclopedistas franceses. [...] Es cosa establecida que a las ideas avanzadas que informan el Romanticismo, cualquiera que sea su origen primitivo, son la Enciclopedia y la Revolución francesa los instrumentos que les proporcionan estructuración intelectual y circulación europea, irradiando hacia España a finales del siglo XVIII sin la menor dificultad. Por si ello, no fuera suficiente, se establecen materialmente en la península con la invasión napoleónica y el rey José I. En consecuencia, la ideología progresista llena el ambiente español durante la mocedad de Espronceda, y en Madrid la recoge este sin que tenga necesidad de volverse hacia lord Byron por ella (Pujals, 1951: 311).

A estas ideas venimos a sumarnos en el presente trabajo, más allá de querer ahondar en aquellas superficiales señales que conectan la "Canción del pirata" de Espronceda con El Corsario de Byron. Entendemos que el reto verdadero estriba en profundizar en esa visión común de mundo expresada de manera conjunta, dispar y territorialmente ajena.

La "Canción del pirata" fue publicada en El Artista (Tomo I, n’ 4, 26 de enero) en 1835 (el mismo año de la propia fundación de la revista por parte de los hermanos Madrazo y Eugenio de Ochoa) con algunas variantes frente a su posterior edición, realizada por José García de Villalta, en 1839. Importante ha sido la labor, como editor y compilador, de José Simón Díaz (1946, 1974) de la enriquecedora —aunque escasa- publicación de El Artista, al que se le uniría el estudio de Rafael Lozano Miralles (1988) para 
poner en situación la creación de una revista que se convertía en tarima de las nuevas formas artísticas imperantes en Europa: perfecto escaparate estético para un poema esproncediano que buscaba horizontes poéticos por descubrir y renovar.

De igual modo, tanto Peers (1973: 417-425) como Romero Tobar (1994: 58-65) estimaron la importancia de esta revista dentro del desarrollo del Romanticismo en España, pues "era en esta época la única revista de Madrid que propiamente puede llamarse romántica” (Peers, 1973: 424). Y no olvidemos, pues, que su esencia liberal, aunque moderada, derivaba, en parte, del exilio español.

Afirma José Enrique García Melero que El Artista asumió esa nueva tendencia artística romántica, de perfil "anticlásico" o, como el propio Espronceda diría, clasiquino 4 : es decir, revolucionario, que pretendió la doble labor de "La difusión de la literatura romántica y de su espíritu, y la crítica sistemática del neoclasicismo" (García Melero, 2002: 172). Apreciación que, años antes, ya había apuntado Vicente Llorens al afirmar que El Artista sirvió de medio de difusión a través del cual "Ochoa, Espronceda y Campo Alange dieron la batalla a los dioses y pastores del neoclasicismo español" (Llorens, 2006: 99). Por tanto, no solo sirvió como atalaya desde la que contrarrestar un estilo que, a su juicio, estaba acabado, sino también como plataforma desde la que proponer y divulgar el arte incipiente en Europa. Dato revelador, pues, porque nuevamente nos situaría ante un Espronceda más en clave de correspondencia que en la de dependencia. Sirva de ejemplo el hecho de que el mismo año de 1835 se publicaba en la revista un fragmento de The Siege of Corinth de Byron, traducido (aunque con bastante anterioridad, en 1827) por Telesforo de Trueba. Por tanto, no solo la muerte de Fernando VII en 1833, sino también la caída del gobierno de Martínez de la Rosa en mayo de 1835 (y los graves problemas económicos que lastraron al país), propiciaron una defensa de las nuevas ideas, no solo en lo político (hecho que afectaría de manera concreta a Espronceda) sino incluso en lo literario, como se

4. Véase el artículo de Espronceda titulado "El pastor clasiquino", publicado en El Artista (entrega XXI; año 1835: 251-252). Aunque somos conscientes de que este texto no queda completamente aislado en el panorama literario de la época ni en la propia consideración del autor pacense, pues del mismo modo se pronunciaba en sus artículos publicados en El Siglo: "Poesía" (nº 2, 24 de enero de 1834: 3-4) e "Influencia del gobierno sobre la poesía" ( $n^{\circ} 12,28$ de febrero de 1834: 3-4). Todo este material bibliográfico puede cotejarse y consultarse en la edición de las Obras Completas de José de Espronceda, publicadas en 2006, cuya referencia completa puede encontrarse en la bibliografía del presente trabajo. 
desprende de sus artículos publicados por el propio poeta en El Siglo y en El Artista respectivamente.

Se trataría, en consecuencia, de un punto de inflexión para su propia poesía, agotada, quizá, tras una búsqueda infructuosa inicial en los moldes neoclásicos, e incluso en el paradigma poético de Ossián: "El paso siguiente será el enfrentamiento con todos ellos en busca de una salida a su través" (Talens, 1975: 23). Y es que, la crítica esproncediana, actualmente, ya no discute en torno al hecho de que la "Canción del pirata" marcó un nuevo rumbo en su poesía, corroborado por la publicación del resto de Canciones, El Estudiante de Salamanca y el inconcluso Diablo Mundo: "Upon his return after Fernando's death, [Espronceda] initiated a new poetics with the publication of 'La Canción del Pirata"' (Kirkpatrick, 2004: 372). Dicho cambio vendría dado por una actitud rebelde y hostil ante aquellos valores limitados (no tradicionales, sino caducos) y coartadores de la sociedad, de su planteamiento moral y de la carencia de respuestas afines a nuevas inquietudes en el pensamiento humano: un camino irrefrenable hacia la máxima libertad del espíritu (Marrast, 1989: 62). Las reglas clásicas, así como las normas, servían de primeras víctimas de una renovación estética cuyo principal objetivo - y resultado- fue la elección de un lenguaje sencillo y menos marcado por la pomposidad retórica (a pesar de no liberarse del tono grandilocuente): fluidez de emoción unida a una expresión — rítmica, compositiva, significativa - que sirviera de preciso cauce, de horma adecuada a una emoción liberada.

Frente a todo esto, véase que los pastores literarios son aquellos que campan en un valle de paz, con el horizonte verde de los prados en firmeza terrestre, mientras que los piratas (cuya composición léxica ya se nos muestra inversa, $r$ - $t$, con respecto a los pastores) viven en un eterno conflicto, con el paisaje azul (esto es, sin el condicionante de la luz solar) y en territorio fluido e inestable. Es, por tanto, reverso de un modelo tomado como caduco y en fase de acabamiento, por no servir ya de esquema para expresar este nuevo sentimiento interior que arrebata a la realidad una esencia que el interior magnifica, sublima y singulariza. A esta misma superación de los modelos clásicos (como instrumento de captación del mundo y caudal para expresar una percepción neutralizada por el equilibrio de la forma), Carlos Bousoño, por ejemplo, la llamó evolución de lo subjetivo a lo intrasubjetivo, otorgándole la categoría de paso decisivo dentro del pensamiento contemporáneo y base ineludible de 
la posterior poética vanguardista, sobre todo la surrealista (Bousoño, 1981, II: $573-577)^{5}$.

\section{ARQUETIPOS ROMÁNTICOS: EL VIAJE DESORIEN- TADO}

El Romanticismo sintió cierta predilección por la figura del navegante, así como también por la del marginado, la del bandolero o asaltante de caminos. En el pirata se aúnan los valores correspondientes a cada uno de ellos y, quizá, por este motivo, los escritores románticos británicos y franceses mostraron su admiración y su temor de manera pareja. Por ejemplo, Samuel Taylor Coleridge escribía su Rime of the Ancient Mariner en 1799, dedicado a George Shelvoche, marino inglés de principios del siglo XVIII; Thomas de Quincey comentaría -de manera extensa- la vida de los navegantes y el peligro inspirado por los piratas en Confessions of an English Opium-Eater, en 1821. También William Hazlitt hacía referencia a la bravura - por no decir temeridad- de los marineros en algunos de sus ensayos recogidos en The Round Table, igualmente en el año 1821. Mucho más evidente fue la novela de Walter Scott, The Pirate, en 1822, basándose en la conocida y popular obra del capitán Charles Johnson (publicada en 1724), A General History of the Robberies and Murders of the Most Notorious Pirates. Y, sin embargo, raramente se pone en duda la supuesta originalidad de un autor como Scott. De igual modo cabría añadir el poema de John Keats, On the Sea (1817); o el melancólico texto de William Wordsworth, The Sailor's mother (con datación vacilante entre los años 1797 y 1802), y las Novelas e historias maritimas del francés Eugénio Sué (traducidas al español en 1845, pero cuyo tema volvería a redundar en torno a la imagen de los piratas, sus aventuras y desventuras...), etc. Fue Vicente Llorens quien señaló — dejándose llevar por el forzado paso de Espronceda por Francia, como ocurriera con el territorio británico- como curioso antecedente, datado en 1827, el Chants des Pirates de L. M. Fontan, mientras que Marrast (1970: 228) vería ciertos

5. Arnold Hauser había señalado, igualmente, esta característica romántica al entender que, durante este período (que abarca la escritura de Byron más que la de Espronceda) el "arte deja de ser arte social regido por criterios objetivos y convencionales, y se convierte en un arte de expresión propia, creador de sus propios criterios, de acuerdo con los cuales quiere ser juzgado; en una palabra, se convierte en un medio por el que el individuo particular habla a individuos particulares" (1983, II: 327). 
parecidos con la obra - ya citada- de M. de Lovedoveix, L'Ami de la tempête, imitation de Lord Byron (1826). El propio Marrast, de este modo, también contravenía las afirmaciones de Moreno Villa y descartaba la influencia de Le Frégate “La Serícuse” de Vigny (Marrast, 1970: 36-37). No obstante, Marrast también afirmó que parecía arbitrario "considerar que la presencia del joven poeta en Londres y París en determinada época le hiciera inmediata y totalmente permeable a nuevas influencias", pues la obra de los "años de emigración contiene muchos versos antiguos, pero todavía pocos pensamientos nuevos" (Marrast, 1989: 179, 219).

Por tanto, sería una época de transición hacia nuevas y renovadas fórmulas expresivas que irían del sustrato clásico a la libre (o liberada) expresión de la subjetividad creadora del poeta (Carnero, 2010; Martínez Torrón, 2016). Así, estilo y el tono de la "Canción del pirata" no podía ser una simple imitación de uno u otro modelo anterior, sino el resultado de una progresiva y paulatina evolución y asimilación interior. Pero ¿Y por qué no hablar de la influencia de algunos romances de Góngora, tales como "Amarrado al duro barco / en una galera turquesa" o "La desgracia del forzado, / y del cosario la industria", cuyo trasfondo barroco bien pudiera emparentarse con el romántico? La nómina de posibles referencias no puede ser escasa, pues tampoco es privativa ni de una época ni de un autor: baste con apuntar la posible influencia, por ejemplo, del poema “The Fisherman's Song” de José Blanco White, ya que se trata de una idea que guarda cierta lógica, si atendemos que este fue coetáneo de Byron y Scott; y, además, comentó sus obras para lectores españoles en prensa (Reyes Cano, 2000: 28). O, como apuntó Russell P. Sebold, bien pudiera tratarse la posible influencia de Mi navegación de Manuel de Cabanyes, pues en ambos encontramos el mismo "brío juvenil de los navegantes, su intrepidez ante los enemigos y su falta de interés en la riqueza material" (Sebold, 2001: 190). Y tal vez debería pensarse en aquello que Jorge Lasso de la Vega (1863: 37) había sugerido, al señalar la existencia de un género específico, indicando, consecuentemente, a los grandes maestros de su escritura frente a los imitadores ${ }^{6}$, pero, sobre todo, donde entrarían no solo

6. Importante es la observación que este autor costumbrista, con tono patriótico, nos legó, entendiendo que Walter Scott (frente a imitadores como Marryat y Cooper) sería el gran maestro en este género de navegantes, junto a Byron. Sin embargo - y a pesar de su duro juicio sobre aquellos que trataban, a su entender, de imitar la obra de los autores ingleses señalados- consideró Lasso de la Vega que se trataba de un "género difícil, poco conocido por los literatos a causa de su índole, y que por esta misma razón exhausta de recursos y de limitado interés; aserto aventurado, que victoriosamente desmienten las interesantes y agradables 
las obras anteriores, ya señaladas, sino otras posteriores, como las de Paul Duplessis, Los Forbantes o Piratas de las Antillas, Mr. Thiers, Historia del Consulado y del Imperio, Fenimore Cooper, El Corsario rojo, Mr. Christian, Historie des pirates et corsaries de l'Ocean et de la Mediterránee, depuis leur origine jusqu'á nos jours, y así un largo listado de obras que alcanzaron el éxito, hasta dar con las novelas del italiano Emilio Salgari y su personaje Sandokan, enfrentado — como en el caso de Espronceda, pero sin el calificativo de copia, curiosamente- al colonialismo británico.

Fue el propio Robert Marrast quien revelaba la escasa afición de Espronceda a enriquecer su biblioteca personal, "sin embargo, entre los libros que poseía a su muerte, solo encontramos las Fables de John Gay, The Antiquary de Scott, The Corsair y Lara de Byron, estas dos últimas obras posiblemente en una edición publicada en París en 1830" (Marrast, 1989: 178). Si bien, el extenso poema narrativo de Byron, publicado en 1814, mostraba cómo la rebeldía romántica podía ejemplificarse a través de la figura del pirata: ese personaje desarraigado y marginal, que huye de la realidad hacia lugares exóticos y que encarna - también en Esproncedala exaltación del idealismo de la extrema libertad, más prolífica entre los escritores ingleses que en los españoles (Espín, 2011: 111-112); de ahí que se hable, inevitablemente, de influencia cuando el concreto período histórico de España propició actitudes semejantes:

When the despot Ferdinand VII was restored to the throne of Spain in 1814, he signalized his return to power by exiling the Young liberals, some of whom sought a temporary refuge in England. Among them were such future leaders of the Romantic movement as Rivas and Espronceda, who, now on British soil, could come into direct relations with English romanticism and could feel the full forcé of the spell of Byron and Scott (Ford, 1901: 456).

Estamos ante un modelo byroniano, alimentado por la propia conciencia de Espronceda de ser un constante viajero-navegante que no encuentra destino final, debido a las circunstancias políticas que forzaron

producciones de estos ingenios y también de algunos escritores en Francia [Sué, Corbiere], pues debemos ser justos, que han trabajado en este género, aunque no con tanta fortuna" (Lasso de la Vega, 1863: 37). Espronceda estaría, para este autor, en la línea de estos imitadores con escasa fortuna, pero con buena intención creadora. 
un exilio por Europa: "it is not surprising that Espronceda's travellers find themselves lost in the "mar del mundo" in the most existential terms" (Rosenberg, 1989: 631). Ahora bien, no cabría realizar una lectura con tintes biográficos de la "Canción del pirata", pues la figura del propio pirata era más propia de un cliché estético que de un manifiesto de la experiencia estrictamente personal. Por ejemplo, en una carta dirigida a sus padres desde Londres, el 27 de diciembre de 1827, el propio Espronceda afirmaba: "Cuidado no deben ustedes tener ninguno, pues aquí el que no roba o asesina no puede ser nunca perseguido" (2006: 1332). Es decir, todo lo contrario a lo que se le atribuye a la figura del pirata en carne propia.

El héroe byroniano se define por su audacia, su carisma, la osadía de su altivez y la continua expresión de disconformidad ante la sociedad de la época, así como por su personalidad cambiante y caprichosa a veces, junto con su constante desprecio a la moral establecida. Robert Barnard lo describe como "Handsome, licentious, moody, doomed, he carried on his shoulders the burden of unpardonable - nay, unmentionable - sins and he shook his fist at the world order, the world's rules, even the Creator himself" (Barnard, 1993: 94). Pero nos cabe la duda de si estos valores antiheóricos, paradójicamente, no son propios, en sí, de la misma figura del pirata y no tanto de una imagen privativa y derivada del imaginario byroniano. Y más aún cuando Espronceda hace uso de su arquetípica imagen (como también hiciera con la del mendigo, la del reo de muerte o la del verdugo) para dar una original muestra que, por primera vez en la poesía española de aquel período, "afirmase y reivindique con orgullo su independencia frente a la sociedad, su amor a la libertad y, dicho sea en una palabra, su rebelión contra un mundo cuyos intereses y preocupaciones éticas le parecen irrisorios y absurdos" (Marrast, 1970: 37).

El pirata como realidad frente a su figura literaria: ¿qué impera en Espronceda? Este mismo debate, fundamentado, claro está, por la propia idiosincrasia de su dual imagen, parece decantar la preponderancia de lo segundo sobre lo primero. Baste con tener presente la inclinación de incluir la "Canción del pirata" como composición poética en libros infantiles y juveniles: nada subversivo impera en ellos y lo que queda, en cuanto a imagen, bien puede asociarse al juego simbólico, a la interpretación más o menos neutra de su rebeldía, de su afición a la muerte y al desafío. Lectura, en todo caso, que viene de una lejanía afectiva evidente frente a la amenaza de la piratería naval, pero ¿Cómo se veía en el siglo XIX a los piratas? 
¿Qué valores encarnaban? ¿Sobre qué aspectos se fue construyendo su imagen arquetípica?

Muchos son los relatos (costumbristas o no) sobre la piratería en el siglo XIX: sin duda, había sido un problema que amenazaba la estabilidad del navegante, pero, sobre todo, se les hacía, en buena medida, culpable de la debacle económica y militar de la corona española. Los abordajes en el océanos Índico y Atlántico tenían fines políticos, con el gobierno inglés pactando acuerdos con estos mercenarios del mar para que limaran las rutas comerciales españolas. De igual modo, el Mediterráneo —como ya había ocurrido siglos atrás - tenía la constante amenaza turca. Es decir, España se veía franqueada por una amenaza (además de sus contiendas con Francia e Inglaterra) invisible, constante y que, de algún modo, encarnaba valores de libertad y de libertinaje a un mismo tiempo.

Frente al evidente éxito en aquella época de libros que trataban las aventuras y desventuras de marineros, piratas y comerciantes, hemos tomado dos textos cuya intención no era exactamente literaria, sino cronística, aunque lo segundo siempre se vería complementado (e incluso suplantado en algunos momentos) por lo primero. Cierto es que la fecha de publicación de sendos libros difiere sobremanera de la de publicación del poema de Espronceda, pero es precisamente esa distancia temporal, sin llegar a ser excesiva, la que permitía ver con mayor claridad los valores históricos y literarios sobre los que se había ido construyendo la imagen del pirata: de las conclusiones bien pudiera desprenderse la doble consideración de si Espronceda siguió realmente el texto de Byron o si, por el contrario, los dos poetas llegaron a un punto común por sendas diferentes. Recordemos que Jorge Lasso de la Vega publicaba en $1863 \mathrm{su}$ extenso libro La Marina Real de España. A fines del siglo XVIII y principios del XIX. Memorias de Familia, Tipos, Escenas y Cuadros de costumbres, apuntes y materiales para la historia de la marina española, cuyo título, en efecto, ya nos apuntaba muy claramente esa revisión costumbrista a la que aludíamos. De igual modo, Justo Zaragoza publicaba en 1883 su libro Piraterías y agresiones de los ingleses y de otros pueblos de Europa en la América Española, desde el siglo XVI al XVIII, deducidas de las obras de D. Dioniosio de Alsedo y Herrera. Dos libros, dos antecedentes, que tratan el tema de la piratería desde un doble plano: como tipos y como amenaza.

Especialmente reseñable resulta la definición del pirata que realizó el propio Justo Zaragoza para comenzar su estudio: lejos de la visión 
ennoblecida del pirata homérico (no olvidemos que Ulises se convierte en pirata, junto a su tripulación, por la necesidad de sobrevivir en alta mar), se nos advertía de la evidente conexión que existía entre estos asaltantes o ladrones marinos y lo maligno que dirigía los pasos del hombre hacia su provecho al margen de la ley cívica:

La palabra española PIRATA, hija legítima de la latina PIRATA, como esta parece haberlo sido de la griega PEIRATES, se aplica entre nosotros al ladrón que anda robando por el mar, y metafóricamente al sujeto cruel $y$ despiadado que no se compadece de los trabajos de otro. Guillermo Blackstone, publicista inglés, concreto y sobrio como buen sajón, dice que «el crimen de concreto de PIRATERÍA, o robo y depredación en alta mar, es una ofensa a las más sagradas leyes de la sociedad, y denomina al pirata "hostis humani generi", es decir, enemigo del género humano; $y$ Lord Lowell observa que para los piratas no hay estado de paz, pues en todo tiempo han sido los enemigos de todas las naciones y se les sujeta, por tanto, universalmente a las medidas más severas de la guerra.

Estas definiciones parecen bastante explicitas para conocer al sujeto tal cual fuera, y por si no se creyeran suficientes, añadiré la de una autoridad irrecusable y testigo de mayor excepción; la del francés o flamenco Alejandro Olivero Exmelin, nombrado por los nuestros Esquemeling, a quien las desgracias arrastraron a ejercer la vida pirática para ganar el importe de su libertad, inscribiéndose al efecto, con otros incitados por la sed del oro, "en el inicuo orden de los piratas o salteadores de la mar;" [sic.] a los que dice "no podía darles otro nombre que el de piratas, por no ser mantenidos, ni depender de ningún soberano Príncipe" (Zaragoza, 1883: 1-2).

Sin duda, conocer al "sujeto tal cual fuera" nos devuelve la imagen de un renegado de la justicia humana que antepone su bien personal al bienestar común de sus semejantes. Jorge Lasso de la Vega, en cambio, lejos de fundamentarse en las aproximaciones de comentaristas ingleses 
y franceses, cargaba contra ellos, culpándoles de manipular - y acaso ensalzar injustamente- la imagen del pirata y, sobre todo, la representación de la nación española como enemiga de estos adalides de la libertad, pues España era víctima de sus ataques y no una causa justificada —afirmabapara que existiesen como representación que encarnara la resistencia más aguda frente al decadente imperio español:

Sin embargo, es muy común en el mundo, en las modernas sociedades, guiadas por un espíritu que pretende ser filosófico, aceptar, confundir en muchos casos esta especie de valor (que condenan las leyes divinas y humanas y la verdadera filosofía como contrario al orden social), no solo disculpando a los que delinquen, o atenuando con singular lenidad tales hechos, sino también a veces elogiando a sus autores como héroes, con menosprecio de las leyes divinas $y$ humanas (Lasso de la Vega, 1863: 598)

No criticaba Lasso de la Vega la figura del pirata, sino la filosofía romántica que había hecho apología de tal figura como emblema de una actitud: malditismo romántico que se convertía en degeneración de unos principios morales injustificados e, incluso, antipatrióticos, según el autor. Porque para España la traición de Trafalgar tenía, en la piratería, una de las claves más determinantes en su fatal resultado final. Evidentemente, tras esta acusación surgían en el texto los nombres de Byron, de Scott, de Cooper y- cómo no- el de Espronceda, cuya "Canción del pirata" se citaba por partida doble $(1863: 594,827)$ y de manera extensa. Por tanto, la definición del pirata como ser social distaba mucho de la del héroe $y, \sin$ embargo, todavía hoy se cita al corsario de Byron como tal: evidentemente porque lo literario prima sobre lo real (Montaner Bueno, 2013: 1-4). Por este motivo, cuando Lasso de la Vega vendrá a definirnos exactamente los aspectos más resaltables del pirata, dirá de ellos:

Asaltantes imprevistos, rivales de las más siniestras tempestades, burlándose del naufragio y pródigos de una vida que el azar alimentaba, se hacían grandes por el terror, merecían el nombre de azote de Dios, y se sepultaban unos en pos de otros en los excesos del mal o en las venganzas del 
mundo. Piratas del Mediterráneo, forbantes del Atlántico, su origen es incierto [...]

De este especie eran los hombres cuya historia referimos: seres corrompidos, arrojados de la sociedad humana, que infestaban con sus vicios, su inmoralidad, sus instintos hostiles y feroces [...] Esos falsos filósofos, poseídos de un loco orgullo, sostenidos con el miserable asentimiento de los que tienen por espiritu fuerte, o la abyecta aprobación de la ciega muchedumbre de sus secuaces que los aplaude, permanecerán mudos y absortos al ver el término fatal de aquellos criminales, y el suceso verdaderamente providencial que puso fin a sus maldades (Lasso de la Vega, 1863: 600, 608-609).

Esta imagen del pirata cabría dirigirla hacia lo literario, precisamente en un trayecto inverso al de Lasso de la Vega: el esquema más elemental de su figura había que encontrarlo en la alegoría tradicional de la vida como viaje marítimo, aunque otros mitemas, tales como el naufragio, la embarcación de la muerte o el hombre frente a las fuerzas de la naturaleza, vendrían a enriquecer, ampliar y dar profundidad a un esquema simbólico ampliamente reconocido. Se añadirían otros dos modelos, mucho más acordes al pensamiento romántico, como el navegante a bordo de un barco que no encuentra su rumbo y aquel que escapa de las contiendas de la sociedad. Así lo había testimoniado el poeta y crítico W. H. Auden en su interpretación sobre la iconografía del mar en su ensayo The Enchafed Flood or The Romantic Inocography of the Sea (1950): el símbolo del barco "is only used as a metaphor for society in danger from within or without. When society is normal the image is the City or the Garden. That is where people want and ought to be [...] A voyage, therefore, is a necessary evil, a crossing of that which separates or estranges" (Auden, 1950: 7). Si bien, el motivo simbólico del barco resulta extenso en su desarrollo y vasto en su significación. Lo que resulta evidente es que los valores del pirata, como tripulante de ese barco, forzosamente están modificándose en su representación, pues si, por un lado, él era la amenaza del mar, ahora era la sociedad la que amenazaba un estilo de vida, una idiosincrasia que corría el riesgo de extinguirse: es aquí, pues, cuando surge la lectura alternativa del corsario o del pirata como héroe, pues su esencia genuina y su libertad 
absoluta son lugares de resistencia frente a la modernidad alienante y destructora de la individualidad (Sebold, 2010: 63-65).

Barco y pirata forman una unidad basada en una relación de dependencia y complementariedad. Son, por tanto, formas análogas e indisociables. Esta reflexión resulta visible y aplicable en el poema esproncediano, donde el bergantín, desde la primera estrofa, adapta y adopta la actitud de su capitán. Hombre y máquina navegan: uno desafiando los límites de lo humano; el otro rompiendo los límites del mar. Uno y otro son, al fin, imagen y reflejo de una misma idea. Sin embargo, en el poema de Byron el barco carece de valor, pues lo realmente importante es la acción del corsario y no su medio de navegación: tan solo encontramos una referencia, con el poema sumamente avanzado, a su bajel, al que tilda de "incauto". Porque mientras el pirata de Espronceda ahonda en lo existencial, el byroniano lo hace en lo histórico-social, ganando, en consecuencia, el doble sentido de su disidencia, catalogada como demoníaca: hostil ante el hombre y ante Dios, tal y como apuntaba Derek Flitter en su estudio en torno a la recepción de Byron en España, pues para este "The lack of a shaping religious context leads Cardwell to view Espronceda's political rebellion as in essence a metaphysical revolt. Once more like Byron, he argues, Espronceda creates a counter-text to the texts he is using, adapting and exploiting" (Flitter, 2004: 139). Así, el poema esproncediano nos revela a un pirata que se adentra en la incesante búsqueda de la aventura, de la lucha, del desafío, mientras que el de Byron está inmerso en ella, vive en ella: su encuentro no es consecuencia de un anhelo, sino de una realidad que en el caso de Espronceda no se da.

Como ha afirmado Juan Eduardo Cirlot, el sentido más profundo de la navegación

nos es dado por Pompeyo el Grande al decir: "Vivir no es necesario: navegar, si'”. Con ello quiso descomponer la existencia en dos estructuras fundamentales: por vivir entendía vivir para sí o en sí; por navegar, vivir para trascender, lo que, desde su ángulo pesimista, denominó Nietzsche: "Vivir para desaparecer" (Cirlot, 2005: 328).

En este sentido, el poema de Espronceda muestra una mayor intención de navegar (aunque desafiante y con espíritu combativo), porque 
renuncia a someterse al colectivo. En consecuencia, adentrarse representa una aventura personal. Así lo interpreta también Esteban Pujals, quien indica que "en Byron no es un hombre solo, sino un grupo de corsarios los que se expresan" (1951: 478). En Espronceda, es la imagen del solitario que se acerca a los límites de su propio destino. De hecho, vemos que el corsario de Byron tiene "tripulación"; solo con el "bajel" cuenta el español". El primero se enfrenta al poder establecido, mientras que el segundo busca o anhela enfrentarse a él: acción frente a intención. Pero en el caso de Espronceda la reducción de la acción a su simple intención tendría una singular lectura de fondo, pues como afirma Marrast:

Espronceda es el único escritor de su generación que demuestra la imposibilidad de conciliar la experiencia terrestre con la creencia en un mundo justo y armonioso. Para ello, como ya lo dijo Larra, habría que rechazar unas tradiciones caducas, que cambiar radicalmente las costumbres, que establecer una ética nueva conforme con la problemática del progreso y de la libertad individual, política, industrial, estética. Fue también el solo poeta que supo expresar el "desasosiego mortal" de que hablaba "Fígaro” (Marrast, 1989: 67).

7. Sobre la diferente jerarquía interna de los piratas y su consecuente clasificación, resulta especialmente útil la definición que realiza Lasso de la Vega, coincidiendo, por otro lado, con la de Justo Zaragoza (1883: 10). De esta descripción que realiza el autor puede desprenderse la singularidad (temible) de los dos capitanes, el de Byron y el de Espronceda, frente al resto de tripulantes de la embarcación. Como adalides que son, deben dar muestra de su liderazgo y de la genialidad que atesoran por encima de lo mezquino: están por encima de lo material y sus inquietudes son, en consecuencias, otras. Esto explica la importancia que tienen los dos autores de resaltar la categoría de los navegantes, pues no son piratas singulares, sometidos, igualmente, a unas reglas superiores a ellos: “Aquellos piratas, sin embargo, podían considerarse divididos en tres clases o categorías esenciales. Correspondían a la primera especie los principales autores, que figuraron en el alzamiento. Dos actores del drama criminal que convirtió el buque negro en pirata, y en cuyos actos se retrataba siempre la insultante altivez, la amenaza siempre armada, siempre pronta a dar la muerte, con la más leve causa. // La segunda se componía de hombre groseros, propensos al mal, a la usurpación y la violencia; pero débiles para inaugurar el crimen, aunque secuaces del mal ejemplo, cuyo número se engruesa por lo común, en todas las asociaciones de esta índole, por hombres descreídos, desalmados, bajos y embrutecidos por la más grosera ignorancia, que son los que forman la masa en las revoluciones y grandes desórdenes sociales. // El resto de aquella extraña asociación lo componían los tímidos, hombres nacidos para obedecer al que osadamente les impone su voluntad o su capricho, cuyo móvil es la codicia y el despojo, respetando solo la fuerza" (Lasso de la Vega, 1863: 590-591). Resulta evidente y es esta la idea que tratamos de desarrollar que Byron representa el mundo pirata de un modo más acorde, en su conducta y acción, con el personaje real, mientras que Espronceda lo hace desde una imagen muy desgajada ya de ese modelo histórico, filtrado, de todos modos, por muchos clichés costumbristas. 
Cierto es que el texto byroniano parte de esa renuncia (y superación) a lo caduco y que el poema de Espronceda no lo interpreta desde la perspectiva más subversiva sino desde la imposible conciliación entre provecho personal y consecuencia social; de ahí que el pirata esproncediano renuncie a las riquezas, a lo material, al efecto más inmediato y efímero de sus fechorías:

En las presas
yo divido
lo cogido
por igual.
Solo quiero
por riqueza
la belleza
sin rival.

Pues en verdad - y es así como se nos apunta desde la propia estructura del poema- es su "barco mi tesoro" y no lo que el ser humano puede ofrecer: aspecto, este, en el que coincide con el corsario de Byron. Pero si el primero principalmente renuncia a lo pragmático, el segundo lo hará de lo racional. Ambos se sienten desarraigados, liberados de lo convencional y, en consecuencia, libres ante la muerte, que está convertida finalmente - como fuera típico en el Romanticismo - en aliada, frente al sufrimiento de la vida (Argelli, 2010: 251-252). En este sentido el personaje dramático de Don Álvaro, del Duque de Rivas, no anda tampoco muy lejos: la muerte viene a jugar un papel revelador al ser principal pórtico de la memoria, de la pervivencia en los otros, porque la vida solo deja víctimas. En consecuencia, el pirata es el anuncio de la misma muerte: el ángel castigador que imparte una injusticia solo comparable con la de Dios al concederle al hombre una vida llamada a su olvido, a su desintegración en la nada del tiempo. Y es aquí donde Espronceda, frente a Byron, manifiesta una mayor coherencia simbólica dentro de toda su producción, pues ¿Qué es un verdugo? ¿Y un mendigo? ¿Y un reo de muerte? Las Canciones daban una visión plural de esta problemática subyacente, parcialmente, en la "Canción del pirata", de ahí que su representación se alejara, considerablemente, de aquel modelo trazado, por ejemplo, por Lasso de la Vega o por Justo Zaragoza (más próximos al pirata de Byron) 
y se acercara a una figura más literaturizada y simbólica.

\section{UNA COMPARACIÓN ENTRE PIRATAS: HÉROE, ANTI- HÉROE Y VALORES SIMBÓLICOS}

Afirma Robert Marrast que José de Espronceda confiaba fehacientemente en el papel de literato como guía que condujese a los hombres por la vía del progreso e iluminara su camino hacia el porvenir:

"Un grande [sic.] hombre - dijo Espronceda en su primera conferencia de literatura comparada pronunciada en 1839- en la idea general de su siglo más una idea propia y peculiar que ordene y dirija el impulso de la primera". Esta concepción coincide con las de Víctor Hugo, Lamartine y Vigny después de 1830 y con la del mismo Heine. Mientras tanto, Ochoa y sus amigos en 1835-1836, y más tarde Zorrilla, defienden un romanticismo seudohistórico y arcaizante derivado de la primitiva Romantik alemana y artificial porque es puramente esteticista, del que decididamente se apartó Espronceda a partir de la Canción del Pirata (Marrast, 1989: 61-62).

Una implicación social que hizo ver, en algunos casos, una lucha política tras esa apología del pirata, pero sobre la que oscilaba una lectura en clave simbólica — como apuntábamos- del poema. Sirva de ejemplo, nuevamente, el valor simbólico del barco para refrendar esta lectura: la modernidad implica un imposible retorno al tiempo del pasado. Por tanto, el desafío frente al presente resulta constante, ya que la ruptura se convierte en su propia tradición al mismo tiempo que busca romper con esta.

El conflicto es base fundamental en el desarrollo de esa modernidad que impele al hombre hacia el futuro, sin respuestas que fundamenten y justifiquen la deriva existencial que padece. Dentro de la alegoría de la vida como navegación se corren dos riesgos: la destrucción (frente al triunfo del océano) o el retroceso (el estancamiento). Consecuentemente, la destrucción lleva al dolor y al temor, mientras que el retroceso, provocado por el temor, lleva al dolor: he ahí la paradoja del ser humano, acechado por un destino cruel, por una infatigable lucha y por una desorientación 
aguda. El pirata esproncediano, como el corsario byroniano, se convierte en guía providencial de ese avance, pues es aquel que desafía a la muerte, no cree en el dolor y muestra el camino hacia el horizonte abierto y por descubrir.

La elección de la imagen del filibustero no resulta azarosa si atendemos a la poderosa razón de su presencia: la modernidad priva al hombre del regreso homérico — de ahí el sentimiento de nostalgia que tanto caracteriza al Romanticismo (Sebold, 2010: 64) - del mismo modo que el pirata renuncia al regreso conciliador. Su paso, como el del tiempo presente, solo deja rastro de muerte: satanismo, lo interpretaron García Velasco (2004: 269-271) y Jean-René Aymes (1998). Otros, en cambio, prefirieron ver signos de ese malditismo derivado del barroco, e, incluso, como señal evidente de ese destino ineludible del poeta como mediador, pues como sostiene Guillermo Carnero:

El poeta es, por lo tanto y según una convicción muy romántica, testigo de excepción de todas las tragedias $y$ destinos humanos; las distingue y las comprende, además de sentirlas en su misma carne y espíritu; se convierte así en un paradigma del destino globalizado de la humanidad, siendo el cortejo de demonios un arquetipo de la sociedad y el mundo (Carnero, 1974: 72).

El pirata, pues, rompería con la hegemonía imaginaria de una realidad regeneradora, cerrada y cuyos principios correctores vendrían a imponer un orden lógico a la existencia, enfrascada en un morir-renacer constante. Negar la veracidad de ese dogma significaba renunciar al lado divinizado del yo, pero no al espiritual; es decir, renovar los valores de antaño, caducos y opresores cuyo esplendor solo advertían el engaño de la vida material y las claves de interpretación de esa misma materia como reflejo de una imperfección quimérica. Baste recordar el verso que cierra el estribillo del poema esproncediano: "mi única patria la mar"; mientras que el corsario de Byron afirma que "Solo el infatigable peregrino / de esos caminos líquidos sin huellas".

Visto así, existe cierta correspondencia con la caída luciferina que, en su versión más social y contemporánea (aunque acorde al Luzbel de 
Paradise Lost de John Milton ${ }^{8}$ ), se enfrenta a su auténtico destino trágico, perfectamente sintetizado por Enrique Gil Calvo: "el de verse obligado a ser al mismo tiempo un héroe justo e injusto, un héroe limpio y sucio a la vez, al estar llamado por los suyos a hacer tanto el bien como el mal en su nombre" (2006: 191), de ahí —explicará más adelante el propio Gil Calvo- el carácter tan contradictorio de estos tipos o héroes, obligados a conciliar, con su acción, principios antagónicos. Y sobre este mismo esquema caben personajes, tan conectados, como el corsario de Byron y el de Conrad, o el pirata de Espronceda y el de Scott. No es la máscara lo que se hereda, sino su valor simbólico: su eterno conflicto con el mundo exterior representado, a veces como océano. De ahí que tanto en Byron como en Espronceda no exista una representación del horizonte marino en calma, sino en actitud embravecida, agitado y destructor. Pero si Bécquer, años más tarde — superado, claro está, el Romanticismo- se enfrentaba a esa "Sacudimiento extraño / que agita las ideas" con su "Gigante voz que el caos / ordena en el cerebro" de su Rima III, el poeta pacense tratará de dominar ese océano y someterlo al poder de su nombre, pues como afirmó Guénon -y recogió Cirlot (2005: 329) — "La conquista de la gran paz es figurada bajo la forma de una navegación" (de ahí su valor como emblema religioso cristiano). Por tanto, si el mar es símbolo de lo misterioso, en consecuencia, dominar la revelación es atravesar la espesura azul del paisaje, sentirla vibrar con su fricción y no estudiarla de un modo racional. Lo primero abogaba por la comunión; lo segundo por la comunicación

El pirata esproncediano - frente al de Byron- comunica cielo y mar ("no corta el mar, sino vuela"), mientras que el byroniano apunta a la revelación de lo oculto en las entrañas del abismo marino, de ahí que sean constantes las referencias a la muerte, al entierro o sepultura: ese

8. Las referencias a la figura satánica en el Romanticismo inglés son evidentes en obras como The Statesman's Manual (1816) de Samuel T. Coleridge, Lectures on the English Poets (1818) de Hazlitt, Prometheus Unbound (1820) de Percy Shelley, etc. Por supuesto, en la obra de Byron resultará especialmente significativa (por ejemplo, en los versos iniciales de Childe Harold's Pilgrimage, de 1812), del mismo modo que Espronceda convertirá a Luzbel en fuente de inspiración en sus dos obras más caracterizadoras: El estudiante de Salamanca (1837- 1840) y El Diablo Mundo (1841). De nuevo Guillermo Carnero advierte sobre el auténtico satanismo romántico, aplicado no solo al poeta pacense sino también al resto de autores del período: "Podría aventurarse la hipótesis de que, del mismo modo que el Satán de Milton se siente desplazado de una dignidad que cree merecer por derecho de naturaleza, el poeta romántico, postergado por una sociedad en la que empieza a no tener función, se identifica con él. La sociedad del XIX, dirá muy claramente Espronceda en numerosas ocasiones, desprecia, ignora o martiriza a los grandes hombres que nacen en su seno" (Carnero, 1974: 72). Efectivamente, la lectura de Carnero de un texto como El Diablo Mundo bien puede aplicarse a la "Canción del pirata", donde el yo debe desmarcarse de las leyes del hombre para dignificar su esencia y su memoria: un gesto que ya hemos calificado de paradójico en su expresión. 
hundirse hacia la profundidad del océano es el único regreso permitido al navegante. Pero el pirata de Espronceda se diferencia una vez más por su individualidad: según Esteban Pujals, su imagen, destacada en la popa del navío, (entonando su desafiadora canción a la luz de la luna) es más lograda que el coro de corsarios isleños cantando a orillas del mar (1951: 479). Este pirata, por su parte, contempla la vastedad de lo celeste: viento, truenos, vuelo y, sobre todo, el mástil.

No olvidemos que, en cuanto símbolo, el mástil entra dentro de la asociación del eje del mundo, por su conexión entre lo terrestre y lo celeste: una imagen del árbol cósmico que eleva al hombre hasta su verdad más absoluta. Por ello las embarcaciones con un mástil (o semejantes) se asocian a lo funerario, adquiriendo un notorio valor trascendente. Sin duda, en la "Canción del pirata" el gesto más violento del poema lo encontramos, precisamente, en relación a este mástil, con lo que, de nuevo, se reincide en la idea de ese mensaje oscuro y tenso que asume testificar el poeta: "Y al mismo que me condene / colgaré de alguna antena / quizá en su propio navío".

Aunque más curioso resulta que, tanto lo funerario como lo celeste y lo terrestre, se asocien mediante la presencia de otro de los grandes símbolos del Romanticismo: la luna. Afirma Cirlot que la barca, cuya forma simula a una luna menguante, se asocia a los dos astros que coronan el día y la noche: por un lado, el esplendor del navío que ha dominado la tempestad (el sol); por otro, la embarcación que se adentra en los horizontes de lo misterioso, en el mundo de las transformaciones (la luna). Y en este sentido el poema de Espronceda nos presenta a un bergantín que, más que navegar, vuela (gesto, por otro lado, muy quijotesco si recordamos el pasaje de Clavileño), dominado por un navegante llamado el Temido. Es decir, ya existe una doble transformación simbólica, justamente cuando:
La luna en el mar rïela, en la lona gime el viento, y alza en blando movimiento olas de plata y azul.

Todo queda transformado. Es por eso que, acto seguido, el capitán pirata ve a un lado Asia, al otro Europa y enfrente Estambul: la comunión de los espacios cuya mediación depende del barco-pirata, a través del 
cual el capitán (poeta) no aplica unas reglas ni unas leyes tradicionales (visible en la propia forma estrófica del poema), sino una sensibilidad que capte la oscura y honda palpitación de la vida. Por su parte, el corsario de Byron, igualmente, une tierra y cielo, transformando las olas gigantes en montañas que el intrépido navegante corona: pero este corsario toma del árbol sus frutos, en un gesto mucho más subversivo si atendemos al episodio bíblico de la manzana y el Árbol de la Sabiduría. Por tanto, si en Espronceda el gesto más tenso se convierte en una provocación revestida de anhelo, en Byron este deseo se convierte en acción continua, en modo de vivir más auténtico: quizá sea este el principal motivo, por encima de las presencias ocasionales de algunos personajes, que los determine en desventajosa comparación entre el poeta inglés y el español. Por ejemplo, si Byron exclama “iQué es la muerte!”, Espronceda lo hará con un “¿Qué es la vida?": el punto de vista, pues, cambia entre ambos, pues si el primero reflexiona (las pocas veces) desde esa misma acción que ha sido su vida, llena de sinsabores, de lucha, de conflicto permanente; el segundo lo hará con la vista puesta en el sendero que ha recorrer y conquistar, desde la libertad de las reglas humanas y de las pulsiones pusilánimes del mediocre anonimato (visible, también, en el texto de Byron).

Uno y otro se ven inmersos en una lucha insatisfecha constantemente a pesar del riesgo que asumen: el límite de las posibilidades de la existencia se muestra débil frente al deseo. Este desasosiego romántico formó parte del ideario estético y existencial de la época, pero también enlazaba con la descripción del pirata como ser sumido en una constante insatisfacción, como revelaba el texto de Lasso de la Vega, en el que afirmaba:

unos hombres entregados a vida tan azarosa, cuyo ánimo se halla siempre ajustado por los contrastes que ofrece el tránsito intempestivo del sosiego a los peligros, llegan a temer la fibra dificil de conmover, y para excitar su atención son necesarias sensaciones irritantes, hechos singulares $y$ atroces, donde domine lo exagerado, lo terrorifico y maravilloso (Lasso de la Vega, 1863: 113).

Ahora bien, esta imagen (mucho más próxima al corsario byroniano que al pirata de Espronceda) resulta un tanto llamativa si atendemos que la libertad representada en sendos poemas se expresa en términos 
insatisfactorios en su trasfondo. Russell P. Sebold, tomando de referencia el poema de Cabanyes, interpretó esto mismo como una actitud próxima al estoicismo de Fray Luis de León (2001: 191) ${ }^{9}$, pero más parece consecuencia de ese hastío existencial tan romántico que una renuncia de los bienes materiales desde un planteamiento afín al aura mediocritas estoico: no pretende expresar (o anhelar) equilibrio, pues precisamente se intenta superar esa barrera conformista del pensamiento conservador. Sin duda, la satisfacción interior es producto de una libertad que busca perpetuarse en el mar, es decir, lejos de lo humano (visto como límite) y esto nos lleva a una soledad profunda, tan pretendida como impuesta de manera pareja.

La incomunicación con los hombres parece, finalmente, un rasgo común a los dos textos: el misterio (recordemos cuando Lasso de la Vega nos apuntaba el origen incierto de los piratas) que su riqueza interior envuelve sus palabras lo convierte en el prototipo del incomprendido, del marginalizado socialmente, tal y como el poeta se sentía en una sociedad cuyo pragmatismo y pensamiento materialista había cargado entre las clases medias y altas. El pirata era la amenaza más evidente de ese mundo mercantilista que comenzaba a desarrollarse potencialmente, aunque no tanto en España como en otros países extranjeros. Byron lo interpretó desde una economía e ideología dominantes, que convertían al hombre en un insaciable conspirador de las libertades humanas a la sombra. Espronceda, cuyo marco económico nacional resultaba muy distinto, lo expresó bajo otros parámetros mucho más generales y cuyo fundamento no fue otro que el de buscar "la belleza / sin rival", con lo que no rechazaba solo un sistema social (más o menos sugerido) sino, sobre todo, unos principios estéticos incapaces de dar forma y testimonio al genio creador, al navegante singular, al espíritu sin par.

En consecuencia, el corsario de Byron atiende más a la figura real del navegante proscrito e intenta transformarlo en emblema simbólico de una lucha existencial y filosófica. Por su parte, el pirata esproncediano, en cambio, tiene como punto de origen esa imagen simbólica del personaje y busca, finalmente, trascender sus valores hasta sublimarlos en belleza sin rival, en una divina libertad, en una patria sin fin, pues "la actitud de

9. Para la relación entre Fray Luis de León y José de Espronceda véase el interesante estudio de Antonio Ramajo (2003), quien se apoya en una revisión del sustrato horaciano existente en ambos poetas. 
Byron en la vida fue sin duda más indócil que la de Espronceda, en cambio, en el arte el poeta español es más agresivo que el británico: si no más filosófica y profunda, la rebeldía de Espronceda se yergue más altanera y audaz" (Pujals, 1951: 432). De todos modos, resulta indiscutible que las coincidencias entre ambos existen: playas que reciben a los piratas, reyes de los mares, estrépito de cañones, actitudes desafiantes y jactanciosas ante la muerte ${ }^{10}$, etc. Rasgos que no unen a los dos textos en concreto sino que están - y forman parte- dentro de las representaciones de los piratas, pues nada concreto los define: Francis Drake, enemigo reconocido de la flota española, se convierte en el inglés, como el capitán del barco pasa a llamarse el Temido, sin traer a la memoria famosos piratas (muy acordes con el perfil descrito por el poema) como Turbulio o James Brooke, la leyenda del Barco Maldito (fantasma errante de los mares) sumamente popular desde mediados del siglo XVII, ni la fama de Antonio Foste, patrón de lancha del famoso barco Terrible, popular por haber resistido valientemente el ataque inglés en 1805; e incluso la existencia de un barco inglés llamado Temeraire y que contaba con más de cien cañones, etc. Todo está revestido de una representación del pirata más estética y, por tanto, más idealizada y alejada de la realidad, propia, además, del folklore popular ${ }^{11}$ : una forma forjada en la fragua de lo literario, de ahí que, inmediatamente, la crítica se inclinase a la búsqueda de referencias literarias anteriores o coetáneas, tratando de observar las correspondencias que existían entre estos textos y creando una relación de dependencia entre ellos que, ciertamente, debe matizarse en algunos casos.

De Byron a Espronceda la principal diferencia estriba en cómo vivieron el Romanticismo en tanto filosofía de vida y el contexto

10. Si volvemos a retomar los comentarios de Lasso de la Vega, pronto descubrimos que esta actitud es definidora de estos tipos y, por tanto, nunca privativa de Byron, ni de Scott o de Vigny, por citar algunos ejemplos: "Cada día más temerarios a fuerza de impunidad, osan desafiar a los señores del mundo; y mientras que en el Capitolio se amontonan las riquezas de tantas provincias conquistadas, un enemigo activísimo e intomable devasta, destruye como el rayo los campos del pueblo rey" (Lasso de la Vega, 1863: 602). Descripción que bien puede relacionarse con los versos esproncedianos: "Que yo soy el rey del mar, / y mi furia es de temer", por ejemplo.

11. Baste citar algunos de los poemas que Jorge Lasso de la Vega recoge en su libro para ver que esta imagen resultaba común en el imaginario popular: por ejemplo, la breve composición que él mismo titulaba "Canción del marinero andaluz" (1863: 547), donde encontramos versos como: "El ancho mar es mi patria, / mi descanso el pelear, / venga uno, vengan ciento, / que lo mismo se me dá! [sic.]”. La semejanza de este poema con el de Espronceda quizá lleve a replantearnos — aunque los materiales son escasos- si la auténtica influencia no es de Byron a Espronceda sino de una serie de canciones populares que Espronceda conociese por transmisión oral (no hay que olvidar su origen familiar andaluz) y, por tanto, no han quedado documentos que así lo puedan corroborar. 
que acogió sus ideas. Los dos encontraron en la imagen del pirata un modelo literaturizado: el primero trató de darle ese perfil dañino de la realidad, mientras que el segundo consiguió elevarlo sobre la monocorde cotidianidad. No es cuestión de copiar, plagiar o piratear, como apuntara Tamara Williams, con tan poco acierto, sino de explorar nuevos horizontes desde lo apuntado con anterioridad. A esto se le llama, habitualmente, influencia; pero todavía no conocemos cultura alguna que no sea un cúmulo de ideas y estéticas llamadas a continuarse y a quebrarse al mismo tiempo: he ahí, pues, la razón del héroe trágico romántico sobre la que coincidieron tanto Byron como Espronceda, a pesar de las distancias geográficas, de los contrastes económicos entre países, de la distinción entre lenguas y, sobre todo, de la significativa e ineludible diferencia de tiempo que media entre ambos.

\section{REFERENCIAS BIBLIOGRÁFICAS}

ALARCÓN, P. A. de (2017). Dos ángeles caídos. Barcelona: www.linkgua-digital.com [20/05/2017].

ARGELLI, A. (2010). "Byronismo e romanticismo spagnolo: i "casi” Cabanyes ed Espronceda". Rivista de Letterature Moderne e Comparate. 63. 3, 251-274.

AUDEN, W. H. (1950). The Enchafed Flood or The Romantic Iconography of the Sea. New York: Random House.

AYMES, J.-R. (1998). "Romanticismo español y espiritualismo: afinidades y antinomias". En Pensamiento y literatura en España en el siglo XIX. Idealismo, Positivismo, Espiritualismo, Yvan Lissorgues, Gonzalo Sobejano (eds.), 21-36. Toulouse: Presses Universitaries du Mirail, Université de Toulouse-Le Mirail,

BARNARD, R. (1993). A Short History of English Literature. Oxford: Blackwell Publishers.

BERNAL, J.L. / LAMA, M.Á. (eds.) (2010). José de Espronceda en su centenario (1808-2008). Almendralejo: Editora Regional de Extremadura.

BOUSOÑO, C. (1981). Épocas literarias y evolución. Edad Media, Romanticismo, Época contemporánea. Vol. II Madrid: Gredos. 
CAMPOS, M. A. (2007). "Vida y obra de Marcos Arróniz”. En Marcos Arróniz: La lira rota, 13-41. México: Universidad Nacional Autónoma de México.

CAPARRÓS ESPERANTE, L. (1989). "Ni Dios, ni Patria, ni Ley: transgresión en las canciones de Espronceda". Castilla 14, 23-39.

CARDWELL, R. A. (ed.) (2004). The reception of Byron in Europe, vol I, II. Nueva York: Thoemmes Continuum. (2004). "El Lord sublime': Byron's legancy in Spain”. En The reception of Byron in Europe, R. A Cardwell (ed.), 144-163. Vol I, II. Nueva York: Thoemmes Continuum

CARNERO, G. (1974). Espronceda. Madrid: Júcar. (2010). "Espronceda, poeta fronterizo". En José de Espronceda en su centenario (1808-2008). J.L. Bernal y M.Á. Lama (eds.), 103-114. Almendralejo: Editora Regional de Extremadura.

CASALDUERO, J. (1983). Espronceda. Madrid: Taurus.

CASCALES MUÑOZ, J. (1914). D. José de Espronceda: su época, su vida y sus obras. Madrid: Biblioteca Hispania.

(1932). El auténtico Espronceda pornográfico y el apócrifo en general. Toledo: Impr. Colegio de Huérfanos.

CHURCHMAN, Philip H. (1909). "Espronceda, Byron and Ossian." Modern Language Notes. Vol 23. 1, 13-16.

(1909b). "Byron and Espronceda". Revue hispanique: recueil consacré à l'étude des langues, des literatures et de l'historie des pays castellans, catalans et portugais 20. 57, 5-210.

CIRLOT, J. E. (2005). Diccionario de símbolos. Madrid: Siruela.

COCHRAN, P. (2005). "Byron's Influence on European Romanticism". En A comparation to European romanticism, Michael Ferber (ed.), 67-85. Carlton, Victoria (Australia): Blackwell Publishing,

DALE, B. (1980). "Byron, Espronceda and the critics". Selecta I, 106-108. ESPÍN, Ma . P. (2011). "La presencia de las literaturas europeas en la obra de Espronceda". En La literatura española del siglo XIX y las literaturas europeas. Coloquio (5²008 Barcelona). E. Rubio, M. Sotelo, V. Trueba, B. Ripoll (eds.), 111-120. Barcelona: PPU Marcial Pons.

FLITTER, D. (2004). "The inmortal Byron» in Spain: radical and Poet of the Sublime". En The reception of Byron in Europe, R. A. Cardwell (ed.), 129-143. Vol I, II. Nueva York: Thoemmes Continuum.

FORD, J.D.M. (1901). "English Influence upon Spanish Literature in the 
Early Part of the Nineteenth Century." PMLA, 16. 3, 453-459.

GARCÍA MELERO, J. E. (2002). Literatura española sobre artes plásticas. Bibliografía aparecida en España durante el s. XIX, vol. II. Madrid: Encuentro.

GARCÍA VELASCO, J. (2004). "El satanismo en Espronceda". Revista de estudios extremeños, 60. 1, 269-280.

GIL CALVO, E. (2006). Máscaras masculinas. Héroes, patriarcas y monstruos. Barcelona: Anagrama.

HAUSER, A. (1983). Historia social de la literatura y del arte, 3 vols. Barcelona: Labor.

KIRKPATRICK, S. (2004). "Romantic poetry". En The Cambridge history of Spanish Literature. D. T. Gies (ed.), 371-380. Cambrigde University Press,

LANDEIRA, R. (LÓPEZ) (1975). "La desilusión poética de Espronceda. Realidad y poesía irreconciliables". Boletín de la Real Academia Española LV, 307-329.

(1985). José de Espronceda. Lincoln (Nebraska): Society of Spanish and Spanish-American Studies.

LASSO DE LA VEGA, J. (1863). La Marina Real de España. A fines del siglo XVIII y principios del XIX. Memorias de Familia. Tipos, escenas y cuadros de costumbres, apuntes y materiales para la historia de la marina española. Tomo II. Mdarid: Imprenta de la Viuda de Calero.

LOZANO MIRALlES, R. (1988). "La prosa narrativa en El Artista". En Romanticismo 3-4. Atti del IV Congresso sul Romanticismo Spagnolo e Ispanoamericano (Bordighera, 9-11 aprile, 1987). La narrativa romántica. E. Caldera (ed.). 171-174. Génova: Istituto di Lingue e Letterature Straniere Centro di Studi sul Romanticismo Iberico.

LLORENS, V. (2006). Liberales y románticos. Una emigración española en Inglaterra (1823-1834). Madrid: Editorial Castalia.

MARRAST, R. (1970). “Introducción”. En José de Espronceda: Poesías líricas y fragmentos épicos, 7-53. Madrid: Editorial Castalia. (1989a). En José de Espronceda y su tiempo. Literatura, sociedad y política en tiempos del romanticismo. Barcelona: Crítica.

(1989b) "Introducción". En José de Espronceda: El estudiante de Salamanca. El Diablo Mundo, 9-82. Madrid: Editorial Castalia.

MARTÍNEZ TORRÓN, D. (1999). La sombra de Espronceda. Mérida: 
Editora Regional de Extremadura.

(2006). "Introducción". En José de Espronceda: Obras Completas, 13-81. Madrid: Cátedra.

(2016). El otro Espronceda. Sevilla: Alfar.

MESONERO ROMANOS, R. de (1951). Escenas Matritenses por El Curioso parlante. V. ed. Madrid: Imprenta y Librería de Gaspar y Roig. MONTANER BUENO, A. (2013). "Tres poetas del siglo XIX: Byron, Espronceda y Hugo. Análisis del desarraigo existencial, de la denuncia social y de la presencia de motivos marginales en sus obras". Tonos Digital: revista electrónica de estudios filológicos, 24, 87 págs. http://www.tonosdigital.es/ojs/index.php/tonos/article/view/908/605 [02/03/2014].

PEERS, E. A. (1973). Historia del movimiento romántico español. Madrid: Gredos.

PUJALS, E. (1951). Espronceda y Lord Byron. Madrid: Consejo Superior de Investigaciones Científicas.

RAMAJO CAÑO, A. (2003). "El sustrato horaciano en un poema romántico: La canción del pirata de Espronceda". Anuario de Estudios Filológicos XXVI, 325-334.

REYES CANO, R. (2000). De Blanco White a la Generación del 27. Estudios de Literatura Española Contemporánea. Huelva: Universidad de Huelva Publicaciones.

RIDENOUR, G. M. (1991). "The Spanish Byron". Studies in Romanticism 30, 213-233.

ROMERO TOBAR, L. (1994). Panorama crítico del romanticismo español. Madrid: Editorial Castalia.

ROSENBERG, J. R. (1989) "Infinite Imperfectibility: Romancing Spanish Romanticism". The Modern Language Review, 84. 3, 621-637.

SEBOLD, R. P. (2001). La perduración de la modalidad clásica. Poesía y prosa españolas de los siglos XVII al XX. Salamanca: Universidad de Salamanca.

(2010). "Espronceda y la maldición del Romanticismo". En José de Espronceda en su centenario (1808-2008). J.L. Bernal y M.Á. Lama (eds.), 63-75. Almendralejo: Editora Regional de Extremadura.

SHAW, D. L. (1988). "Byron and Spain". En Byron and Europe. Renaissance and Modern Studies 32, 45-59.

SIMÓN DÍAZ, J. (ed.) (1946). El Artista (Madrid, 1835-1836). Madrid: 
CSIC.

(1974). "El Artista y su continuador El Renacimiento". Revista de Literatura 73-74, 135-136.

TALENS, J. (1975). El texto plural. Sobre el fragmentarismo romántico: una lectura simbólica de Espronceda. Valencia: Universidad de Valencia.

VALERA, J. (1854). "Del romanticismo en España, y de Espronceda". Revista Española de ambos mundos, tomo II. Madrid: Establecimiento Tipográfico de Mellado, s/p.

WILLIAMS, T. R. (2004). "Literatura al Segundo grado: literariedad y compromiso social en El diario que a diario". En Nicolás Guillén: Hispacidad, Vanguardia y compromise social, M. Barchino, M. Rubio (coords.), 471-482. Cuenca: Universidad de Castilla-La Mancha. YNDURÁIN, D. (1971). Análisis formal de la poesía de Espronceda. Madrid: Taurus.

ZARAGOZA, J. (1883). Piraterías y agresiones de los ingleses y de otros pueblos de Europa en la América Española desde el siglo XVI al XVIII, deducidas de las obras de D. Dionisio de Alsedo y Herrera. Madrid: Imprenta de Manuel G. Hernández, Libertad, 16 duplicado.

Recibido el 29 de mayo de 2017.

Aceptado el 16 de julio de 2017. 
